\title{
An Updated Overview of Low Back Pain Management in Primary Care
}

\author{
Jae-Young Hong ${ }^{1}$, Kwang-Sup Song ${ }^{2}$, Jae Hwan Cho ${ }^{3}$, Jae Hyup Lee ${ }^{4}$ \\ ${ }^{1}$ Department of Orthopedics, Korea University Ansan Hospital, Ansan, Korea \\ ${ }^{2}$ Department of Orthopaedic Surgery, Chung-Ang University College of Medicine, Seoul, Korea \\ ${ }^{3}$ Department of Orthopedic Surgery, Asan Medical Center, University of Ulsan College of Medicine, Seoul, Korea \\ ${ }^{4}$ Department of Orthopedic Surgery, SMG-SNU Boramae Medical Center, Seoul, Korea
}

Currently, guidelines for lower back pain (LBP) treatment are needed. We reviewed the current guidelines and high-quality articles to confirm the LBP guidelines for the Korean Society of Spine Surgery. We searched available databases for high-quality articles in English on LBP published from 2000 to the present year. Literature searches using these guidelines included studies from MEDLINE, the Cochrane Database of Systematic Reviews, the Cochrane Central Register of Controlled Trials, and Embase. We analyzed a total of 132 randomized clinical trials, 116 systematic reviews, 9 meta-analyses, and 4 clinical guideline reviews. We adopted the SIGN checklist for the assessment of article quality. Data were subsequently abstracted by a reviewer and verified. Many treatment options exist for LBP, with a variety of recommendation grades. We assessed the recommendation grade for general behavior, pharmacological therapy, psychological therapy, and specific exercises. This information should be helpful to physicians in the treatment of LBP patients.

Keywords: Lower back pain; Treatment guideline; Recommendation

\section{Introduction}

Currently, there are many guidelines for the treatment of lower back pain (LBP). Many of these guidelines are focused on medication; however, other treatment modalities should also be evaluated [1-4]. In addition, while there are many treatment options for LBP treatment, the majority of options are based upon neuropathic pain and radiculopathy. To create an up-to-date guideline for primary LBP treatments, we reviewed previously published guidelines and added information from recently published high-quality studies.

\section{Materials and Methods}

\section{Data sources and searches}

The literature search included all English-language articles on LBP. We searched MEDLINE and the Cochrane Database of Systematic Reviews for relevant systematic reviews, combining terms for LBP with a search strategy for identifying systematic reviews. When higher-quality systematic reviews were not available for a particular treatment, we conducted additional searches for primary studies of the randomized controlled trials. We excluded trials of LBP associated with neuropathic pain. Due to

Received Nov 29, 2016; Revised Jan 13, 2017; Accepted Jan 26, 2017

Corresponding author: Jae-Young Hong

Department of Orthopedics, Korea University Ansan Hospital, 123 Jeokgeum-ro, Danwon-gu, Ansan 15355, Korea

Tel: +82-31-412-6577, Fax: +82-31-487-9502, E-mail: osspine@korea.ac.kr 
the large number of trials evaluating medications for LBP, our primary source for trials was clinical guideline reviews, systematic reviews, and meta-analyses. When a higher-quality systematic review was not available for a particular intervention, we included all relevant randomized controlled trials. We included randomized controlled trials that met all of the following criteria: (1) reported in English and (2) evaluated a target treatment. We excluded outdated reviews. We also excluded reviews that did not clearly use systematic methods as well as systematic reviews that evaluated target medications but did not report results specifically for patients with LBP. We analyzed a total of 132 randomized controlled trials, 116 systematic reviews, 9 meta-analyses, and 4 clinical guideline reviews.

\section{Data extraction and quality assessment}

An expert panel convened by the Korean Society of Spine Surgery (KSSS) determined which treatments would be included in this review. Data were subsequently abstracted by reviewers and verified. For each trial, we differentiated between acute (4 weeks in duration) and chronic/subacute (4 weeks in duration) LBP. If specific data on the duration of trials were not provided, we relied on the categorization (acute or chronic/subacute) assigned by the articles. We assessed the internal validity (quality) of systematic reviews using the Scottish Intercollegiate Guidelines Network (SIGN) criteria (Table 1) [5]. There were many treatment options for LBP, with a variety of recommendation grades. We assessed recommendation grades for general behavior, pharmacological therapy, psychological therapy, and specific exercises. We assessed the overall strength of evidence for a body of evidence using methods adapted from the SIGN criteria [5]. To evaluate consistency, we classified the conclusions of trials and systematic reviews as $\mathrm{A}, \mathrm{B}, \mathrm{C}$, and $\mathrm{D}$. If we could not determine the recom-

Table1. Recommendation grade for general behavior

\begin{tabular}{lcc} 
& Acute LBP & Chronic LBP \\
Information & I & A \\
Education and self-care & A & A \\
Advice to stay active & A & A \\
Reassure patients & A & B \\
Bed rest & D & A \\
Modified work & I & I \\
\hline
\end{tabular}

LBP, low back pain. mendation level due to the lack of high-quality articles, we defined it as insufficient (I).

\section{Results}

\section{General behavior}

We reviewed six treatment methods for acute and chronic LBP (Table 1). For acute LBP, four unique trials of general behavior and three clinical guideline reviews were included in the review for general behavior [2-4,6-9]. Four trials found clear differences in pain relief with education and self-care and advice to stay active. In addition, there was sufficient evidence from three clinical guideline reviews to support the effectiveness of reassuring patients. However, there was insufficient evidence for bed rest and modified work based upon the available references. For chronic LBP, two higher-quality trials found evidence for effectiveness of education and self-care and the advice to stay active. In addition, two clinical guideline reviews highly supported the use of information, reassuring patients, and bed rest for the treatment of chronic LBP $[1,2,6,8]$.

\section{Pharmacological therapy}

A total of 18 methods for the treatment of acute and chronic LBP were reviewed by the assessment panel [2-4,10-19]. For acute LBP, several randomized trials and higher-quality systematic reviews found non-steroidal anti-inflammatory dru gs (NSAIDs), acetaminophen (AAP), and paracetamol superior for pain relief (Table 2). In addition, three clinical guideline reviews strongly supported the use of these medications. Opioids, benzodiazepines, muscle relaxants, and tricyclic antidepressants showed significant improvement of symptoms in two high-quality systemic reviews as well as three clinical guidelines. In addition, three trials and one clinical guideline review found minimal differences in pain relief with the use of carisoprodol, herbal therapy, thiocolchicoside, and tizanidine. For chronic LBP, several randomized trials and higher-quality systematic reviews found NSAIDs, AAP, paracetamol, opioid, and buprenorphine superior for pain relief. Benzodiazepines, muscle relaxants, tricyclic antidepressants, tapentadol, and pregabalin showed significant improvement of symptoms in seven high-quality studies as well as three clinical guidelines. Other pharmacological therapies were not supported by the references $[1,2,4,11,16,17,19-40]$. 
Table 2. Recommendation grade for pharmacologic therapy

\begin{tabular}{|c|c|c|}
\hline & Acute LBP & Chronic LBP \\
\hline NSAIDs & A & $A$ \\
\hline Acetaminophen & $A$ & $A$ \\
\hline Opioids & $B$ & A \\
\hline Buprenorphine & 1 & A \\
\hline Benzodiazepines & B & B \\
\hline Antiepileptic drugs & B & C \\
\hline Aspirin & I & D \\
\hline Muscle relaxants & B & B \\
\hline Tricyclic antidepressants & B & $\mathrm{B}$ \\
\hline Systemic corticosteroids & 1 & 1 \\
\hline Tapentadol & I & B \\
\hline Glucosamine & 1 & $D$ \\
\hline Adjunctive analgesics & 1 & I \\
\hline Carisoprodol & B & 1 \\
\hline Herbal therapy & B & I \\
\hline Thicolchicoside & B & B \\
\hline Tizanidine & B & I \\
\hline
\end{tabular}

LBP, Iow back pain; NSAIDs, non-steroidal anti-inflammatory drugs.

\section{Psychological therapy}

We reviewed three methods for the treatment of acute and chronic LBP $[1,3,4,16,41-44]$. For acute LBP, the evidence was insufficient from several reviews of clinical guidelines for the effectiveness of psychological therapy (Table 3). For chronic LBP, five higher-quality trials found evidence for the effectiveness of cognitive behavioral therapy. In addition, three clinical guideline reviews highly supported the use of cognitive behavioral therapy. Progressive muscle relaxation was supported by one clinical guideline review, with multidisciplinary treatments supported by one high-quality randomized trial.

\section{Specific exercise}

We reviewed 11 treatment methods for the treatment of acute and chronic LBP [2-4,7,45-52]. For acute LBP, six unique trials of general behavior and two clinical guideline reviews were included in the review of general exercise (Table 4). The evidence was insufficient from several randomized trials and clinical guideline reviews to support the effectiveness of a specific exercise for acute LBP. A total of 12 trials found clear differences in pain relief
Table 3. Recommendation grade for psychological therapy

\begin{tabular}{lcc} 
& Acute LBP & Chronic LBP \\
Cognitive behavioral therapy & I & B \\
$\begin{array}{l}\text { Progressive muscle } \\
\text { relaxation }\end{array}$ & I & B \\
Multidisciplinary treatment & I & B \\
\hline LBP, low back pain. & &
\end{tabular}

Table 4. Recommendation grade for specific exercise

\begin{tabular}{lcc} 
& Acute LBP & Chronic LBP \\
\hline General & C & A \\
\hline Mobilizing & I & C \\
\hline Strengthening & I & C \\
\hline Aerobic & I & B \\
\hline Unsupervised walking & I & C \\
\hline Core stability & I & C \\
\hline Mckenzie & C & C \\
\hline Supervised exercise & D & B \\
\hline Stabilizing & C & B \\
\hline Stretching & C & C \\
\hline Extension & C & C \\
\hline LBP, low back pain. & &
\end{tabular}

with general exercise for chronic LBP. In addition, there was sufficient evidence from two meta-analyses, three systematic reviews, and three clinical guideline reviews to support the effectiveness of general exercise. We identified two randomized trials and two clinical guideline reviews for aquatic and supervised exercise therapy. In addition, seven randomized trials supported the effectiveness of stabilizing exercises. Other treatment options were not supported by the available literature [2-4,46-69].

\section{Discussion}

There were several guidelines for LBP. Most clinical guideline reviews were based upon extensive literature searches. The Cochrane reviews are frequently used as well as databases such as MEDLINE and Embase. As in our study, literature reviews of high-quality trials and previous guidelines are used for additional searches. A variety of committees use different weighting systems and ratings of the available evidence with some variations in the manner recommendations are presented [1-4]. In some reviews, all recommendations are linked with references, 
and in others, a general remark is made for a given recommendation. We reviewed the current guidelines and high-quality articles to confirm the LBP guidelines for the KSSS. The primary aim of this study was the establishment of updated clinical guidelines for the management of LBP in primary care. Clinical guidelines, which focused on interventional or surgical treatment, occupational care settings, or specific subgroups of patients with radicular pain by a specific disease, were not considered. Separate studies need to be undertaken to present an overview for all treatment modalities. SIGN guidelines are developed using an explicit methodology based on three core principles: (1) development is by multidisciplinary, nationally representative groups; (2) a systematic review is conducted to identify and critically appraise the evidence; and (3) recommendations are explicitly linked to the supporting evidence. These principles have remained constant since SIGN was first established. A statement is provided for the implementation of the principles of the GRADE process. SIGN guidelines are based on systematic review of the evidence, undertaken by guideline development group members, and with support from the SIGN Executives [5].

Most published guidelines have discussed a good prognosis of LBP. For patients with longer duration of LBP or recurrent LBP, the prognosis may be less favorable. We reviewed several treatment methods for the treatment of acute and chronic LBP. Support for the consensus meeting on which this article is based was provided by the KSSS group, which received unrestricted support from multiple pharmaceutical companies. There was sufficient evidence from several randomized trials and clinical guideline reviews that support the effectiveness of treatment options. For example, several trials found clear differences in pain relief with general exercise for chronic LBP. In addition, there was sufficient evidence from meta-analyses, systematic reviews, and clinical guideline reviews that support the effectiveness of general exercise. More sophisticated estimates of LBP prognosis may be needed in the future. Recommendations did not support the use of injections, minimally invasive approaches, or surgical procedures for LBP. These treatment options were not included in this review. Future reviewer panels may wish to provide additional guidance on what constitutes appropriate surgical or interventional management and acceptable improvement for various time intervals. Although this does not eliminate the possibility that individual patients may benefit from interventions or surgery, current adherence to these recommendations by clinicians appears minimal.

\section{Conclusions}

We assessed the recommendation grade for the primary treatment of acute and chronic LBP. A variety of recommendation grades were determined for general behavior, pharmacological therapy, psychological therapy, and specific exercises. This analysis should be helpful to physicians in the treatment of LBP.

\section{Conflict of Interest}

No potential conflict of interest relevant to this article was reported.

\section{References}

1. Pillastrini P, Gardenghi I, Bonetti F, et al. An updated overview of clinical guidelines for chronic low back pain management in primary care. Joint Bone Spine 2012;79:176-85.

2. Dagenais S, Tricco AC, Haldeman S. Synthesis of recommendations for the assessment and management of low back pain from recent clinical practice guidelines. Spine J 2010;10:514-29.

3. Koes BW, van Tulder M, Lin CW, Macedo LG, McAuley J, Maher C. An updated overview of clinical guidelines for the management of non-specific low back pain in primary care. Eur Spine J 2010;19:207594.

4. Chou R, Qaseem A, Snow V, et al. Diagnosis and treatment of low back pain: a joint clinical practice guideline from the American College of Physicians and the American Pain Society. Ann Intern Med 2007;147:478-91.

5. Guyatt GH, Oxman AD, Vist GE, et al. GRADE: an emerging consensus on rating quality of evidence and strength of recommendations. BMJ 2008;336:924-6.

6. Albaladejo C, Kovacs FM, Royuela A, del Pino R, Zamora J. The efficacy of a short education program and a short physiotherapy program for treating low back pain in primary care: a cluster randomized trial. Spine (Phila Pa 1976) 2010;35:483-96.

7. Pengel LH, Refshauge KM, Maher CG, Nicholas MK, Herbert RD, McNair P. Physiotherapist-directed exercise, advice, or both for subacute low back pain: a 
randomized trial. Ann Intern Med 2007;146:787-96.

8. Liddle SD, Gracey JH, Baxter GD. Advice for the management of low back pain: a systematic review of randomised controlled trials. Man Ther 2007;12:31027.

9. Traeger AC, Hubscher M, Henschke N, Moseley GL, Lee $\mathrm{H}$, McAuley JH. Effect of primary care-based education on reassurance in patients with acute low back pain: systematic review and meta-analysis. JAMA Intern Med 2015;175:733-43.

10. Hancock MJ, Maher CG, Latimer J, et al. Assessment of diclofenac or spinal manipulative therapy, or both, in addition to recommended first-line treatment for acute low back pain: a randomised controlled trial. Lancet 2007;370:1638-43.

11. Tetsunaga T, Tanaka M, Ozaki T. Efficacy of tramadol-acetaminophen tablets in low back pain patients with depression. J Orthop Sci 2015;20:281-6.

12. Lasko B, Levitt RJ, Rainsford KD, Bouchard S, Rozova A, Robertson S. Extended-release tramadol/ paracetamol in moderate-to-severe pain: a randomized, placebo-controlled study in patients with acute low back pain. Curr Med Res Opin 2012;28:847-57.

13. Perrot S, Krause D, Crozes P, Naim C. Efficacy and tolerability of paracetamol/tramadol $(325 \mathrm{mg} / 37.5$ $\mathrm{mg}$ ) combination treatment compared with tramadol (50 mg) monotherapy in patients with subacute low back pain: a multicenter, randomized, double-blind, parallel-group, 10-day treatment study. Clin Ther 2006;28:1592-606.

14. Williams CM, Maher CG, Latimer J, et al. Efficacy of paracetamol for acute low-back pain: a double-blind, randomised controlled trial. Lancet 2014;384:158696.

15. Ketenci A, Ozcan E, Karamursel S. Assessment of efficacy and psychomotor performances of thiocolchicoside and tizanidine in patients with acute low back pain. Int J Clin Pract 2005;59:764-70.

16. Chou R, Huffman LH; American Pain Society; American College of Physicians. Nonpharmacologic therapies for acute and chronic low back pain: a review of the evidence for an American Pain Society/ American College of Physicians clinical practice guideline. Ann Intern Med 2007;147:492-504.

17. Davies RA, Maher CG, Hancock MJ. A systematic review of paracetamol for non-specific low back pain. Eur Spine J 2008;17:1423-30.
18. Machado GC, Maher CG, Ferreira PH, et al. Efficacy and safety of paracetamol for spinal pain and osteoarthritis: systematic review and meta-analysis of randomised placebo controlled trials. BMJ 2015;350: h1225.

19. Nampiaparampil DE, Nampiaparampil GM, Nampiaparampil RG. Oral opioid analgesics vs. spinal steroid injections in the treatment of low back pain syndromes. Am J Phys Med Rehabil 2012;91:162-76.

20. Lee JH, Lee CS; Ultracet ER Study Group. A randomized, double-blind, placebo-controlled, parallelgroup study to evaluate the efficacy and safety of the extended-release tramadol hydrochloride/acetaminophen fixed-dose combination tablet for the treatment of chronic low back pain. Clin Ther 2013;35:1830-40.

21. Schiphorst Preuper HR, Geertzen JH, van Wijhe M, et al. Do analgesics improve functioning in patients with chronic low back pain? An explorative tripleblinded RCT. Eur Spine J 2014;23:800-6.

22. Hale ME, Dvergsten C, Gimbel J. Efficacy and safety of oxymorphone extended release in chronic low back pain: results of a randomized, double-blind, placebo- and active-controlled phase III study. J Pain 2005;6:21-8.

23. Hale ME, Ahdieh H, Ma T, Rauck R; Oxymorphone ER Study Group 1. Efficacy and safety of OPANA ER (oxymorphone extended release) for relief of moderate to severe chronic low back pain in opioid-experienced patients: a 12-week, randomized, double-blind, placebo-controlled study. J Pain 2007;8:175-84.

24. Katz N, Rauck R, Ahdieh H, et al. A 12-week, randomized, placebo-controlled trial assessing the safety and efficacy of oxymorphone extended release for opioid-naive patients with chronic low back pain. Curr Med Res Opin 2007;23:117-28.

25. Vondrackova D, Leyendecker P, Meissner W, et al. Analgesic efficacy and safety of oxycodone in combination with naloxone as prolonged release tablets in patients with moderate to severe chronic pain. J Pain 2008;9:1144-54.

26. Cloutier C, Taliano J, O’Mahony W, et al. Controlledrelease oxycodone and naloxone in the treatment of chronic low back pain: a placebo-controlled, randomized study. Pain Res Manag 2013;18:75-82.

27. Nalamachu S, Rauck RL, Hale ME, Florete OG Jr, Robinson CY, Farr SJ. A long-term, open-label safety study of single-entity hydrocodone bitartrate extend- 
ed release for the treatment of moderate to severe chronic pain. J Pain Res 2014;7:669-78.

28. Gordon A, Rashiq S, Moulin DE, et al. Buprenorphine transdermal system for opioid therapy in patients with chronic low back pain. Pain Res Manag 2010;15:169-78.

29. Gordon A, Callaghan D, Spink D, et al. Buprenorphine transdermal system in adults with chronic low back pain: a randomized, double-blind, placebocontrolled crossover study, followed by an open-label extension phase. Clin Ther 2010;32:844-60.

30. Steiner DJ, Sitar S, Wen W, et al. Efficacy and safety of the seven-day buprenorphine transdermal system in opioid-naive patients with moderate to severe chronic low back pain: an enriched, randomized, double-blind, placebo-controlled study. J Pain Symptom Manage 2011;42:903-17.

31. Steiner D, Munera C, Hale M, Ripa S, Landau C. Efficacy and safety of buprenorphine transdermal system (BTDS) for chronic moderate to severe low back pain: a randomized, double-blind study. J Pain 2011;12:1163-73.

32. Miller K, Yarlas A, Wen W, et al. Buprenorphine transdermal system and quality of life in opioidexperienced patients with chronic low back pain. Expert Opin Pharmacother 2013;14:269-77.

33. Yarlas A, Miller K, Wen W, et al. A randomized, placebo-controlled study of the impact of the 7-day buprenorphine transdermal system on health-related quality of life in opioid-naive patients with moderateto-severe chronic low back pain. J Pain 2013;14:1423.

34. Katz J, Pennella-Vaughan J, Hetzel RD, Kanazi GE, Dworkin RH. A randomized, placebo-controlled trial of bupropion sustained release in chronic low back pain. J Pain 2005;6:656-61.

35. Wild JE, Grond S, Kuperwasser B, et al. Long-term safety and tolerability of tapentadol extended release for the management of chronic low back pain or osteoarthritis pain. Pain Pract 2010;10:416-27.

36. Buynak R, Shapiro DY, Okamoto A, et al. Efficacy and safety of tapentadol extended release for the management of chronic low back pain: results of a prospective, randomized, double-blind, placebo- and active-controlled Phase III study. Expert Opin Pharmacother 2010;11:1787-804.

37. Wilkens P, Scheel IB, Grundnes O, Hellum C, Storhe- im K. Effect of glucosamine on pain-related disability in patients with chronic low back pain and degenerative lumbar osteoarthritis: a randomized controlled trial. JAMA 2010;304:45-52.

38. Uberall MA, Mueller-Schwefe GH, Terhaag B. Efficacy and safety of flupirtine modified release for the management of moderate to severe chronic low back pain: results of SUPREME, a prospective randomized, double-blind, placebo- and active-controlled parallel-group phase IV study. Curr Med Res Opin 2012;28:1617-34.

39. Romano CL, Romano D, Bonora C, Mineo G. Pregabalin, celecoxib, and their combination for treatment of chronic low-back pain. J Orthop Traumatol 2009; 10:185-91.

40. Urquhart DM, Hoving JL, Assendelft WW, Roland M, van Tulder MW. Antidepressants for non-specific low back pain. Cochrane Database Syst Rev 2008;(1): CD001703.

41. Johnson RE, Jones GT, Wiles NJ, et al. Active exercise, education, and cognitive behavioral therapy for persistent disabling low back pain: a randomized controlled trial. Spine (Phila Pa 1976) 2007;32:157885.

42. Vibe Fersum K, O'Sullivan P, Skouen JS, Smith A, Kvale A. Efficacy of classification-based cognitive functional therapy in patients with non-specific chronic low back pain: a randomized controlled trial. Eur J Pain 2013;17:916-28.

43. Monticone M, Ambrosini E, Rocca B, Magni S, Brivio F, Ferrante S. A multidisciplinary rehabilitation programme improves disability, kinesiophobia and walking ability in subjects with chronic low back pain: results of a randomised controlled pilot study. Eur Spine J 2014;23:2105-13.

44. Smeets RJ, Vlaeyen JW, Hidding A, et al. Active rehabilitation for chronic low back pain: cognitivebehavioral, physical, or both? First direct posttreatment results from a randomized controlled trial [ISRCTN22714229]. BMC Musculoskelet Disord 2006;7:5.

45. Kuukkanen T, Malkia E, Kautiainen H, Pohjolainen T. Effectiveness of a home exercise programme in low back pain: a randomized five-year follow-up study. Physiother Res Int 2007;12:213-24.

46. Hall AM, Maher CG, Lam P, Ferreira M, Latimer J. Tai chi exercise for treatment of pain and disability in 
people with persistent low back pain: a randomized controlled trial. Arthritis Care Res (Hoboken) 2011; 63:1576-83

47. Jones MA, Stratton G, Reilly T, Unnithan VB. Recurrent non-specific low-back pain in adolescents: the role of exercise. Ergonomics 2007;50:1680-8.

48. Hurwitz EL, Morgenstern H, Chiao C. Effects of recreational physical activity and back exercises on low back pain and psychological distress: findings from the UCLA Low Back Pain Study. Am J Public Health 2005;95:1817-24.

49. Kader D, Radha S, Smith F, et al. Evaluation of perifacet injections and paraspinal muscle rehabilitation in treatment of low back pain: a randomised controlled trial. Ortop Traumatol Rehabil 2012;14:251-9.

50. Machado LA, Maher CG, Herbert RD, Clare H, McAuley JH. The effectiveness of the McKenzie method in addition to first-line care for acute low back pain: a randomized controlled trial. BMC Med 2010;8:10

51. Rhee HS, Kim YH, Sung PS. A randomized controlled trial to determine the effect of spinal stabilization exercise intervention based on pain level and standing balance differences in patients with low back pain. Med Sci Monit 2012;18:CR174-81.

52. Pillastrini P, Mugnai R, Bertozzi L, et al. Effectiveness of an at-work exercise program in the prevention and management of neck and low back complaints in nursery school teachers. Ind Health 2009;47:349-54.

53. Ferreira ML, Ferreira PH, Latimer J, et al. Comparison of general exercise, motor control exercise and spinal manipulative therapy for chronic low back pain: a randomized trial. Pain 2007;131:31-7.

54. Koldas Dogan S, Sonel Tur B, Kurtais Y, Atay MB. Comparison of three different approaches in the treatment of chronic low back pain. Clin Rheumatol 2008;27:873-81.

55. Shirado O, Doi T, Akai M, et al. Multicenter randomized controlled trial to evaluate the effect of homebased exercise on patients with chronic low back pain: the Japan low back pain exercise therapy study. Spine (Phila Pa 1976) 2010;35:E811-9.

56. Sertpoyraz F, Eyigor S, Karapolat H, Capaci K, Kirazli Y. Comparison of isokinetic exercise versus standard exercise training in patients with chronic low back pain: a randomized controlled study. Clin Rehabil 2009;23:238-47.
57. Machado LA, Azevedo DC, Capanema MB, Neto TN, Cerceau DM. Client-centered therapy vs exercise therapy for chronic low back pain: a pilot randomized controlled trial in Brazil. Pain Med 2007;8:2518.

58. Jones M, Stratton G, Reilly T, Unnithan V. The efficacy of exercise as an intervention to treat recurrent nonspecific low back pain in adolescents. Pediatr Exerc Sci 2007;19:349-59.

59. Durmus D, Unal M, Kuru O. How effective is a modified exercise program on its own or with back school in chronic low back pain? A randomized-controlled clinical trial. J Back Musculoskelet Rehabil 2014; 27:553-61.

60. Steele J, Bruce-Low S, Smith D, Jessop D, Osborne $\mathrm{N}$. A randomized controlled trial of limited range of motion lumbar extension exercise in chronic low back pain. Spine (Phila Pa 1976) 2013;38:1245-52.

61. Dufour N, Thamsborg G, Oefeldt A, Lundsgaard C, Stender S. Treatment of chronic low back pain: a randomized, clinical trial comparing group-based multidisciplinary biopsychosocial rehabilitation and intensive individual therapist-assisted back muscle strengthening exercises. Spine (Phila Pa 1976) 2010; 35:469-76.

62. Franca FR, Burke TN, Caffaro RR, Ramos LA, Marques AP. Effects of muscular stretching and segmental stabilization on functional disability and pain in patients with chronic low back pain: a randomized, controlled trial. J Manipulative Physiol Ther 2012;35:279-85.

63. Dundar U, Solak O, Yigit I, Evcik D, Kavuncu V. Clinical effectiveness of aquatic exercise to treat chronic low back pain: a randomized controlled trial. Spine (Phila Pa 1976) 2009;34:1436-40.

64. Garcia AN, Costa Lda C, da Silva TM, et al. Effectiveness of back school versus McKenzie exercises in patients with chronic nonspecific low back pain: a randomized controlled trial. Phys Ther 2013;93:72947.

65. Bronfort G, Maiers MJ, Evans RL, et al. Supervised exercise, spinal manipulation, and home exercise for chronic low back pain: a randomized clinical trial. Spine J 2011;11:585-98.

66. Limke JC, Rainville J, Pena E, Childs L. Randomized trial comparing the effects of one set vs two sets of resistance exercises for outpatients with chronic low 
back pain and leg pain. Eur J Phys Rehabil Med 2008; 44:399-405.

67. Kumar S, Negi MP, Sharma VP, Shukla R, Dev R, Mishra UK. Efficacy of two multimodal treatments on physical strength of occupationally subgrouped male with low back pain. J Back Musculoskelet Rehabil 2009;22:179-88.
68. Meng XG, Yue SW. Efficacy of aerobic exercise for treatment of chronic low back pain: a meta-analysis. Am J Phys Med Rehabil 2015;94:358-65.

69. Hayden JA, van Tulder MW, Malmivaara AV, Koes BW. Meta-analysis: exercise therapy for nonspecific low back pain. Ann Intern Med 2005;142:765-75. 